\title{
Biofilm Production of Leptospira spp. Strains
}

\author{
Dayane Olímpia Gomes, Laura Gonçalves da Silva Chagas, Gabriela Bim Ramos, Andreia Zago Ciuffa, Laís Miguel \\ Rezende, Lígia Pinho Cuccato, Thais Fernanda Martins dos Reis, Bruno Cabral Pires \& Anna Monteiro Correia Lima
}

\begin{abstract}
Background: Leptospirosis is a zoonosis that affects many species of mammals and occurs endemically in Brazil. The biofilm matrix provides structure and protection to the biofilm cells working as a physical barrier to antibiotic agents, which are attached or consumed by the matrix components. However, this attribute varies according to the matrix, antimicrobial agent and biofilm age. Leptospira may change morphologically according to environmental conditions, including cell aggregation and biofilm formation. Leptospira can colonize the ducts of kidney from hosts for a long time, forming a biofilm, which is believed to be an important factor for their maintenance in animals and in the environment. Thus, the objective of this research was to determine the biofilm formation capacity of four strains of Leptospira interrogans.

Materials, Methods \& Results: The strains were typified by WHO/FAO/OIE and National Collaborating Center for Reference and Research on Leptospirosis (Kit Biomedical Research, Amsterdam, Netherlands). Leptospira interrogans strains, two isolated from cattle and two isolated from dogs were biofilms tested for adhesion on polystyrene plates, extracellular matrix composition and confocal microscopy. In the plating adhesion test, the suspension was inoculated into 96-well sterile polystyrene microplates with flat bottom at a ratio of 1:200 in $\mathrm{EMJH}$ medium, followed by $24 \mathrm{~h}$ incubation at $28^{\circ} \mathrm{C}$, with medium renewal after $12 \mathrm{~h}$. After this period the wells were washed three times with sterile PBS and following incubation; the plates were dried in the oven at $60^{\circ} \mathrm{C}$ for $30 \mathrm{~min}$ and added $200 \mu \mathrm{L}$ of $1 \%$ violet crystal for five min. Subsequently, the plates were washed with distilled water, after complete removal, $200 \mu \mathrm{L}$ of acetic acid $33 \%$ was added and the readings were performed at $570 \mathrm{~nm}$ in the ELISA reader. The proteins and polysaccharides were quantified in a scraped pooled sample diluted in $0.85 \%$ sterile saline solution to achieve an optimal amount for testing used reagents of the BCA kit. The polysaccharide content was determined by adding into a tube, an aliquot of $0.5 \mathrm{~mL}$ from the pooled sample, $0.5 \mathrm{~mL}$ of phenol and then immediately $2.5 \mathrm{~mL}$ of sulfuric acid. The solution was homogenized and left to react for $15 \mathrm{~min}$ at room temperature. The reading was performed at $490 \mathrm{~nm}$ in ELISA reader. The strains were compared regarding polysaccharides and protein matrices using analysis of variance (ANOVA) and Tukey test. At confocal microscopy the strains were incubated with the tested polypropylene material for $24 \mathrm{~h}$. The materials were washed with sterile phosphate buffer and stained with propidium iodide. The reading was performed using a Laser Scanning Confocal Microscope (Zeiss 710) with laser excitation (488 nm) and 580-680 nm emission filters for propidium iodide (red marking). All strains displayed strong adherence on microplate and the amount of polysaccharides in biofilm was not statistically different among the studied strains, but the amount of protein was significantly different in strain $4(P>0.5)$. The confocal microscopy showed the adherence of the Leptospira spp. strains to polypropylene material after washing.

Discussion: Biofilm production plays an important role in the maintenance of a chronic infection by Leptospira interrogans with renal colonization. The exopolysaccharide (EPS) has various functions, such as checking insolubility in water; giving the three-dimensional conformation of the biofilm; protecting cells from physical (mechanical action, irradiation and temperature variations), chemical.
\end{abstract}

Keywords: biofilm formation, extracellular matrix, Leptospira interrogans. 


\section{INTRODUCTION}

Leptospirosis is a zoonotic disease with world wide distribution and endemic in tropical countries. Leptospiras can survive for several days in the environment, under ideal $\mathrm{pH}$, temperature and humidity conditions. Infected animals may carry bacteria in kidneys, and shed it in the urine, transmitting to other animals, humans and contaminating the environment

Biofilm formation is characterized by the expression of an extracellular matrix, which has structural and physiological functions. The biofilm matrix provides structure and protection to the biofilm cells [14,21] working as a physical barrier to antibiotic agents, which are attached or consumed by the matrix components. However, this attribute varies according to the matrix, antimicrobial agent and biofilm age [13].

Although biofilm formation may differ even for a single strain grown under different environmental conditions, the structure and composition of the extracellular matrix follows common principles. Typically, a biofilm consists of amyloid, adhesive fimbriae, surface protein, exopolysaccharide, and extracellular DNA [8,21].

Biofilms have been shown to be a major cause of cross-contamination of food products and disease transmission $[16,18]$. Leptospira can change its morphology according to environmental conditions, including cell aggregation [18] and biofilm formation [17]. Biofilm formation by Leptospira sp. can play an important role in their ability to survive in different environmental habitats including their host [17].

However, there are few studies on biofilm formation by leptospires, in spite of their high pathogenicity. This study aimed to evaluate the biofilmforming ability of Leptospira spp. strains isolated from infected dogs and cattle.

\section{MATERIALS AND METHODS}

Leptospira spp. strains

Leptospira interrogans strains (two isolated from cattle and two isolated from dogs) were provided by Laboratory of Bacterial Zoonosis from Universidade de São Paulo (USP), São Paulo, Brazil. Bacteria were maintained in Ellinghausen-McCullough (EMJH) and semi-solid FLETCHER media at $28^{\circ} \mathrm{C}$. The strains were typified by WHO/FAO/OIE and National Collaborating Center for Reference and Research on Leptospirosis ( Kit Biomedical Research) ${ }^{1}$.
Seroreativity of strains was classified by microscopic agglutination test (MAT) with monoclonal antibodies [10]. The pulsed-field gel electrophoresis was performed as previously described [5].

Strains were identified as: strain $n^{\circ} 1$ : M5/90 1990 Leptospira interrogans serovar Icterohaemorragiae/Copenhageni; strain nº2: L06 2001 Leptospira interrogans serovar Canicola in dogs; strain nº 3 : L014 2001 Leptospira interrogans serovar Canicola; and strain $n^{\circ} 4$ : L010 2001 Leptospira interrogans serovar Icterohaemorragiae/Copenhageni in cattle. All tests were performed in triplicate with three replications.

Plate adhesion test

The plating adhesion test was performed as previously described with few modifications [5]. The bacteria were cultured individually in EMJH medium supplemented with $10 \%$ rabbit serum for seven days. Then, the suspension was inoculated into 96 well sterile polystyrene microplates with flat bottom at a ratio of 1:200 in EMJH medium, followed by $24 \mathrm{~h}$ incubation at $28^{\circ} \mathrm{C}$, with medium renewal after $12 \mathrm{~h}$. The wells were washed three times with sterile PBS (10 mM, pH 7.4) and following incubation; the plates were dried in the oven at $60^{\circ} \mathrm{C}$ for $30 \mathrm{~min}$. Then, $200 \mu \mathrm{L}$ of $1 \%$ violet crystal was added for $5 \mathrm{~min}$. Subsequently, the plates were washed with distilled water, after complete removal, $200 \mu \mathrm{L}$ of acetic acid 33\% was added and the readings were performed at $570 \mathrm{~nm}$ in the ELISA reader $^{2}$. Non-inoculated wells with EMJH worked as control. Strains of biofilm producing bacteria had absorbance greater than 0.1. Each strain was tested in triplicate, three times. The intensity of the slime production was scored as follows: strong (greater than 0.3), moderate $(>0.2$ and $<0.3)$ and low $(>0.1$ and $<0.2)[6]$

\section{Quantification of matrix proteins}

The proteins and polysaccharides were quantified in a scraped pooled sample diluted in $0.85 \%$ sterile saline solution to achieve an optimal amount for testing. A $12.5 \mu \mathrm{L}$ aliquot of the pooled sample, diluted at the same ratio with sterile saline, was added to a 96well microplate. Then, $200 \mu \mathrm{L}$ of the mixed reagents of the BCA kit (Sigma) ${ }^{3}$ was added, homogenized for 30 $\mathrm{s}$ and incubated for $30 \mathrm{~min}$ at room temperature. The readings were performed at $562 \mathrm{~nm}$ in ELISA reader ${ }^{2}$, and a phosphate buffer as blank, as demonstrated with adaptations for Leptospira [1]. 
Quantification of polysaccharides - phenol-sulfuric acid method

The polysaccharide content was determined by adding into a tube, an aliquot of $0.5 \mathrm{~mL}$ from the pooled sample, $0.5 \mathrm{~mL}$ of phenol $(50 \mathrm{~g} / \mathrm{L})$ and then immediately $2.5 \mathrm{~mL}$ of sulfuric acid (95-97\% - Isofar). The solution was homogenized and left to react for 15 $\mathrm{min}$ at room temperature. The reading was performed at $490 \mathrm{~nm}$ in ELISA reader ${ }^{2}$ using a phosphate buffer as blank [7]. The strains were compared regarding polysaccharides and protein matrices using analysis of variance (ANOVA) and Tukey test.

\section{Confocal microscopy}

The strains of Leptospira interrogans were incubated with the tested polypropylene material in 8-well sterile plate with flat bottom at 1: 200 in EMJH at $28^{\circ} \mathrm{C}$ for $24 \mathrm{~h}$, with medium renewal after $12 \mathrm{~h}$. In the Histology Laboratory from Universidade Federal de Uberlândia (UFU), the materials were washed with sterile phosphate buffer and stained with propidium iodide. The reading was performed using a Laser Scanning Confocal Microscope (Zeiss 710) ${ }^{4}$ with laser excitation $(488 \mathrm{~nm})$ and 580-680nm emission filters for propidium iodide (red marking).

\section{RESULTS}

All strains were identified as biofilm producers by adhesion test in microplate and classified as strong, since biomass absorbance was greater than 0.3. Analysis of the biofilm matrix showed higher concentration of protein compared to polysaccharide, according to (Figure 1). The amount of polysaccharides in biofilm was not statistically different among the studied strains, but the amount of protein was significantly different in strain $4(P>0.5)$

Shows the images of the confocal microscopy and the adherence of the Leptospira spp. strains to polypropylene material after washing (Figure 2).

\section{DISCUSSION}

All strains showed strong adherence to plates after one day of incubation. This result differs from a previous study in which two strains of Leptospira sp., one saprophytic and other pathogenic were tested in 12-well polypropylene plates, washed and stained with crystal violet, with readings $600 \mathrm{~nm}$, and after 2 days of incubation a light adhesion was observed [17].

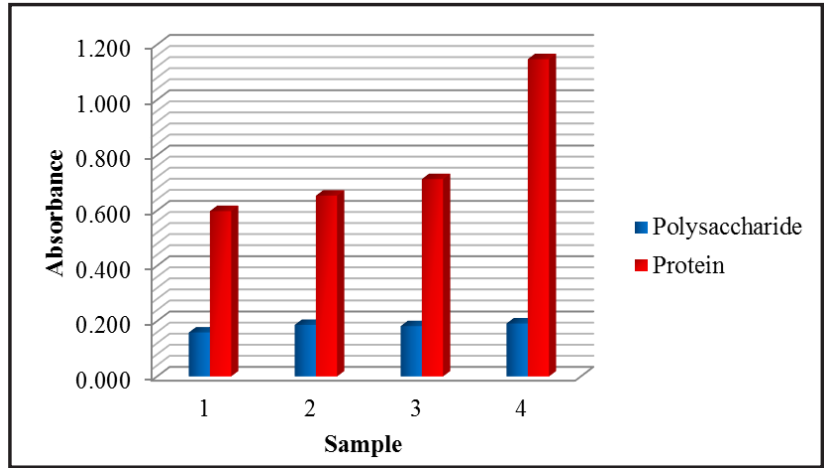

Figure 1. Biochemical composition of protein and polysaccharide extracellular matrix of Leptospira interrogans strains, Canicola and Icterohaemorrhagiae/ Copenhageni serovars tested by BCA Kit and phenol-sulfuric acid method.
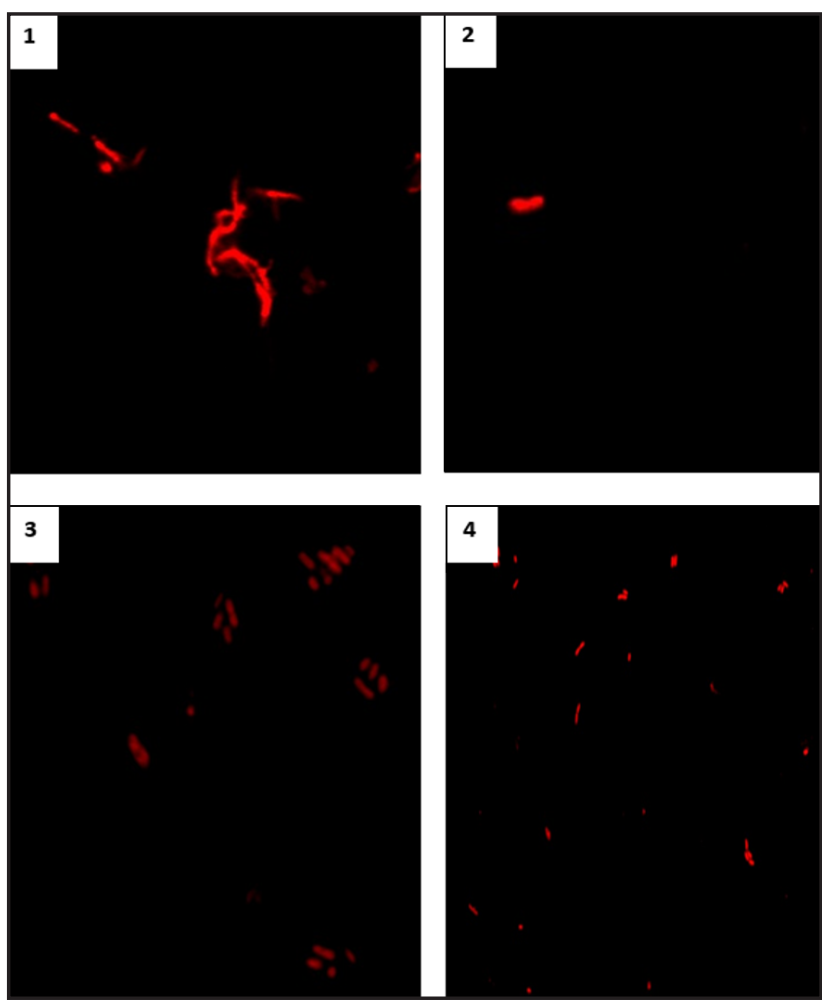

Figure 2. Images of the confocal microscopy method showing the biofilms of the Leptospira interrogans strains serovar Canicola and Icterohaemorragiae/Copenhageni on polypropylene material. The pictures are ordered in the sequence: Strains 1 and 2, and below strains 3 and 4 .

A recent study tested 21 Leptospira spp. strains in 96 well polystyrene plates. The results showed adherence in vitro for 8 strains [11] and reported $600 \mathrm{~nm}$ reading after $48 \mathrm{~h}$, similar to this study, with $570 \mathrm{~nm}$ readings after $24 \mathrm{~h}$ for four adherent strains.

The exopolysaccharide (EPS) has various functions, such as checking insolubility in water; giving the three-dimensional conformation of the biofilm; protecting cells from physical (mechanical action, irradiation and temperature variations), chemical (chemical agents used in industrial hygiene procedures) stress (competi- 
tors and predators) biological; and the role in the nutrient input [4,9]. To this end, the EPS brings doubtless benefits to the survival of microorganisms despite being a large burden to the cell, due to the energy required for its synthesis $[6,12]$. Therefore, the characterization of the biofilm matrix is important for understanding the pathogenicity of strains.

The biofilm matrices had higher amount of protein than polysaccharide. In general, the protein biofilms have better mechanical properties than those based on polysaccharides [3]. Also, proteins are important to the biofilm maturation process since they interact with special polysaccharides, named polysaccharide intercellular adhesion (PIA) in cell-cell aggregation [15].

The leptospiral colonization in placental tissues of mice proved the cell aggregation ability of pathogenic Leptospira sp. in vivo [2]. Also, the biofilm can play an important role in maintaining a chronic infection by Leptospira interrogans with kidney colonization [17].

\section{CONCLUSION}

Strains of Leptospira interrogans serovar Canicola and Icterohamorrhagiae / Copenhageni from dogs and cattle formed biofilms and showed high adherence in the tested materials.

\section{MANUFACTURERS}

${ }^{1}$ Kit Biomedical Research. Amsterdam, Netherlands.

${ }^{2}$ Thermo Scientific Multiskan Co. Hudson, NH, USA.

${ }^{3}$ Sigma Chemical Co. St. Louis, MO, USA.

${ }^{4}$ Carl Zeiss AG Corporate. Oberkochen, Baden-Württemberg, Germany.

Declaration of interest. The authors report no conflicts of interest. The authors alone are responsible for the content and writing of the paper.

\section{REFERENCES}

Azeredo J., Visser J. \& Oliveira R. 1999. Exopolymers in bacterial adhesion: interpretation in terms of DLVO and XDLVO theories. Colloids and Surfaces B: Biointerfaces. 14: 141-148.

Brihuega B., Samartino L., Auteri C., Venzano A. \& Caimi K. 2012. In vivo cell aggregations of a recent swine biofilmforming isolate of Leptospira interrogans strain from Argentina. Revista Argentina Microbiologia. 44: 138-143.

Chen C.T. 1999. Linear system theory and design. Oxford: Oxford University Press, 334p.

Cheng G., Zhang Z., Chen S., Bryers J.D. \& Jiang S. 2007. Inhibition of bacterial adhesion and biofilm formation on zwitterionic surfaces. Biomaterials. 2829: 4192-4199.

Cucarella C., Colano C., Valle J., Amorena B., Lasa I. \& Penades P. 2001. Bap, a Staphylococcus aureus surface protein involved in biofilm formation. Journal of Bacteriology. 183: 2888-2896.

Cucarella C., Tormo M.A., Ubeda C., Trotonda M.P., Monzón M., Peris C., Amorena B., Lasa I. \& Penadés J.R. 2004. Role of biofilm associated protein bap in the pathogenesis of bovine Staphylococcus aureus. Infection and Immunity. 7: 2177-2185.

Dubois M., Giles K.A., Hamilton J.K., Rebers P.A. \& Smith F. 1956. Colorimetric method for determination of sugars and related substances. Analytical Chemistry. 28: 350-356.

Dueholm M.S., Sondergaard M.T., Nilsson M., Christiansen G., Stensballe A., Overgaard M.T., Givskov M., TolkerNielsen T., Otzen D.E. \& Nielsen P.H. 2013. Expression of Fap amyloids in Pseudomonas aeruginosa, P. fluorescens, and P. putida results in aggregation and increased biofilm formation. MicrobiologyOpen. 2: 365-382.

James G.A., Beaudette L. \& Costerton J.W. 1995. Interspecies bacterial interactions in biofilms. Journal of Industrial Microbiology and Biotechnology. 15: 257-262.

Korver H., Kolk A.H.J., Vingerhoed J., Leeuwen J.V. \& Terpstra W.J. 1988. Classification of the serovars of Icterohaemorrhagiae serogroup by monoclonal antibodies. Israel Journal of Veterinary Medicine. 44: 15-18.

Kumar K.V., Lall C., Raj R.V., Vedhagiri K. \& Vijayachari P. 2015. Co-existence and survival of pathogenic leptospires by formation of biofilm with Azospirillum. FEMS Microbiology Ecology. 91: 1-11.

Latasa C., Solano C., Penadés J.R. \& Lasa I. 2006. Biofilm-associated proteins. Comptes Rendus Biologies. 329: 849-857. Mah T.F. 2012. Regulating antibiotic tolerance within biofilm microcolonies. Journal of Bacteriology. 194: 4791-4792.

Mann E.E. \& Wozniak D.J. 2012. Pseudomonas biofilm matrix composition and niche biology. FEMS Microbiology Reviews. 36: 893-916.

Planchon S., Gaillard-Martinie B., Dordet-Frisoni E., Bellon-Fontaine M.N., Leroy S., Labadie J., Hébraud M. \& Talon R. 2006. Formation of biofilm by Staphylococcus xylosus. International Journal of Food Microbiology. 109: 88-96. 
D.O. Gomes, L.G.S. Chagas, G.B. Ramos, et al. 2018. Biofilm Production of Leptospira spp. Strains.

Pompermayer D.M.C. \& Gaylarde C.C. 2000. The influence of temperature on the adhesion of mixed cultures of Staphylococcus aureus and Escherichia coli to polypropylene. Food Microbiol. 17: 361-365.

Ristow P., Bourhy P., Kerneis S., Schmitt C., Prevost M.C., Lilenbaum W. \& Picardeau M. 2008. Biofilm formation by saprophytic and pathogenic leptospires. Microbiology. 154: 1309-1317.

Shi X. \& Zhu X. 2009. Biofilm formation and food safety in food industries. Trends in Food Science and Technology. 20: 407-413.

Truccolo J., Charavay F., Merien F. \& Perolat P. 2002. Quantitative PCR assay to evaluate ampicillin, ofloxacin, and doxycycline for treatment of experimental leptospirosis. Antimicrobial Agents and Chemotherapy. 46: 848-853.

Trueba G., Zapata S., Madrid K., Cullen P. \& Haake D. 2004. Cell aggregation: a mechanism of pathogenic Leptospira to survive in fresh water. International Microbiology. 7: 35-40.

Whitchurch C.B., Tolker-Nielsen T., Ragas P.C. \& Mattick J.S. 2002. Extracellular DNA required for bacterial biofilm formation. Science. 295: 1487. 